\title{
What My 1-Year-Old Son Has Taught Me about Pharmacist Practice
}

\author{
Jason Howorko
}

$P^{o}$ oop happens . . . as often as 8 to 10 times a day . . really! If I have learned anything personally over the past year, it has been due to the arrival of my son, Alexander. As I have learned to change diapers, to comfort an unhappy child, and to not laugh out loud when food is thrown at my lovely wife, I have also learned a lot about our profession.

Make friends: In our profession, we need a cohesive community. Meet your colleagues and other pharmacy professionals in your department, hospital, city or town, province, professional society, and country. Together we are a strong voice.

Remember to share: Although Alex "stealing" his friend Rylee's toy truck can sometimes be quite a spectacle, it reminds me that we all need to remember to share. Each of us is doing amazing things in our individual practices. Remember to publish it, present it as a poster, email it to a PSN (Pharmacy Specialty Network), share it with the world!

Embrace the little things: Although my son first said "DaDa" when he was chasing the cat, it was still a small victory. Remember to embrace and cherish the little things we do and the small successes we have.

Take small steps to achieve big changes: I remember Alex's first few steps. For several weeks afterward, he stumbled and fell each time he tried to walk, but he never became discouraged. Now that he's running everywhere, he reminds me that we need to start small to reach our ultimate goals.

Have fun: Every once in a while, we all need to take a step back and just have fun. Although playing peek-a-boo with a colleague might be questioned in the patient care area, one could consider attending a Canadian Society of Hospital Pharmacists (CSHP) conference. You can learn and have fun, too!

Be prepared to deal with change: Just as a child grows and develops, so does our profession. Every day a child develops a new ability and challenges the limits of his or her world. The day my crawling son somehow got the remote control off the couch by pulling a pillow toward him, I knew my world would never be the same . . outsmarted by a 9 -month-old! Change can come quickly, and sometimes we just need to roll with it.

Although we cannot

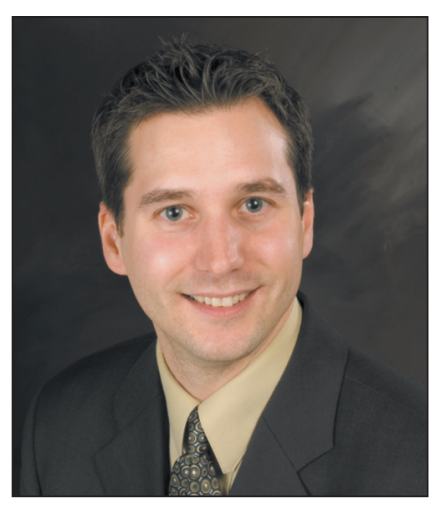
anticipate everything, we can and must quickly adapt to the new opportunities and challenges that present themselves. We need to build relationships, grow, learn, develop, adapt, share, take some small steps, fall, take some big leaps, embrace the little things, and remember to have fun.

When I look into my son's eyes, I dream of a world of opportunities for him. Today, I also see opportunities for our profession that are within our grasp. We can make a difference, one Society, one provincial Branch, one pharmacy department, and one pharmacist at a time. I can only imagine where we will be in another 10 years.

It has been an absolute pleasure serving as a CSHP presidential officer for the past 3 years. I will forever cherish the memories and the new friendships that I've gained through this position, just as I treasure the experience of becoming a new dad. Cheers!

Jason Howorko, BSP, BSC, ACPR, is Past President and External Liaison for the CSHP. 